\title{
Low levels of plasma endothelin- $I$ in patients with retinitis pigmentosa
}

This article was published in the following Dove Press journal:

Clinical Ophthalmology

3 June 2010

Number of times this article has been viewed

\author{
Hiroshi Ohguro' \\ Yukihiko Mashima ${ }^{2}$ \\ Mitsuru Nakazawa ${ }^{3}$ \\ 'Department of Ophthalmology, \\ Sapporo Medical University School \\ of Medicine, ${ }^{2}$ Department of \\ Ophthalmology, Keio University \\ School of Medicine, ${ }^{3}$ Department of \\ Ophthalmology, Hirosaki University \\ School of Medicine, Japan
}

Correspondence: Hiroshi Ohguro Department of Ophthalmology, Sapporo Medical University School of Medicine, South-I, West-16, Chuo-ku, Sapporo, Japan 060-8543

Tel +8 I II $61 \mid$ I 1 II extn 3435

Fax +8I II 6136575

Email ooguro@sapmed.ac.jp
Purpose: The aim of this study was to elucidate the role of endothelin-1 (ET-1) in the pathophysiology of retinitis pigmentosa (RP).

Methods: Plasma ET-1 levels and ophthalmic features in $50 \mathrm{RP}$ patients were compared with those in 20 healthy-eye control subjects. Plasma ET-1 concentrations were determined using a commercially available enzyme-linked immunosorbent assay kit.

Results: Mean plasma ET-1 levels of RP patients $(1.88 \pm 0.56 \mathrm{pg} / \mathrm{mL})$ were significantly lower than those of control subjects $(2.30 \pm 0.30 \mathrm{pg} / \mathrm{mL}$, Mann-Whitney's $U$ test; $P<0.01)$. However, ET-1 concentrations varied markedly in each patient. Among RP patients, a significant correlation of ET-1 concentrations was not observed in terms of its hereditary forms or other clinical factors.

Conclusion: ET-1 may be important in the pathogenesis of RP, and measurement of its plasma concentrations may also contribute to additional insights into the retinal hemodynamics of RP.

Keywords: endothelin-1, retinitis pigmentosa, retinal hemodynamics

\section{Introduction}

Retinitis pigmentosa (RP) is a heterogeneous disease group of progressive hereditary retinal degeneration. It is clinically characterized by night blindness and peripheral concentric visual field defects and abnormal electroretinogram responses due to photoreceptor cell degeneration. ${ }^{1}$ Markedly decreased retinal blood flow has been reported. ${ }^{2-5}$ This suggests that impaired retinal hemodynamics may be involved in the pathophysiology of RP. However, the pathologic and biochemical mechanisms involved have not yet been elucidated. A preliminary study has demonstrated that plasma endothelin-1 (ET-1), a very potent vasoconstrictor, is significantly elevated in RP patients when compared with control subjects. ${ }^{6}$ It was suggested that elevated ET-1 could lead to vasoconstriction and decrease in retinal blood flow, resulting in further deterioration of retinal degeneration. Thus, it is of much interest to test plasma ET-1 levels in various types of RP patients to elucidate the pathophysiologic significance of ET-1 in the etiology of RP. In the present study, we investigated serum ET-1 levels in 50 RP patients of differing genotypes and at various stages of the disease.

\section{Patients and methods Patients}

Fifty RP patients (32 sporadic RP [SRP], nine autosomal dominant RP [ADRP], seven autosomal recessive RP [ARRP], one X-linked RP, one Biedl-Bardet 
Table I Clinical characteristics and serum ET-I levels in 50 RP patients

\begin{tabular}{|c|c|c|c|c|}
\hline Age & Visual acuity (R/L) & Genetic type & Visual field MD (dB) (R/L) & ET-I (pg/mL) \\
\hline 71 & $\mathrm{HM} / \mathrm{HM}$ & ADRP & n.d. & 2.14 \\
\hline 45 & $0.02 / 0.02$ & ADRP & n.d. & 1.57 \\
\hline 49 & $0.06 / 0.06$ & ADRP & n.d. & 2.3 \\
\hline 50 & $\mathrm{HM} / 0.3$ & ADRP & n.d. & 0.71 \\
\hline 50 & $0.3 / 0.3$ & ADRP & $-35.36 /-35.26$ & 2.63 \\
\hline 43 & $0.1 / 0.4$ & ADRP & $-12.14 /-9.12$ & 1.9 \\
\hline 72 & $0.4 / 0.4$ & ADRP & $-16.32 /-16.33$ & 1.99 \\
\hline 60 & $0.5 / 0.5$ & ADRP & $-16.21 /-19.49$ & 1.66 \\
\hline 60 & $0.7 / 0.7$ & ADRP & $-24.34 /-24.60$ & 1.87 \\
\hline 52 & $\mathrm{HM} / \mathrm{HM}$ & ARRP & $-35.06 /-35.18$ & 2.55 \\
\hline 61 & $0.02 / 0.02$ & ARRP & n.d. & 1.95 \\
\hline 72 & $0.05 / 0.05$ & ARRP & n.d. & 2.18 \\
\hline 70 & $0.1 / 0.1$ & ARRP & n.d. & 1.54 \\
\hline 49 & $0.15 / 0.15$ & ARRP & $-19.90 /-19,58$ & 1.8 \\
\hline 61 & $0.2 / 0.2$ & ARRP & $-31.39 /-37.72$ & 1.42 \\
\hline 50 & $1.0 / 0.9$ & ARP & $-0.49 /-1.78$ & 2.36 \\
\hline 63 & $0.4 / 0.4$ & XLRP carrier & n.d. & 0.83 \\
\hline 23 & $0.05 / 0.09$ & Biedl-Bardet & n.d. & 1.81 \\
\hline 75 & LP/LP & SP & n.d. & 2.09 \\
\hline 65 & $\mathrm{HM} / \mathrm{HM}$ & SP & n.d. & 2.13 \\
\hline 34 & $0.03 / 0.02$ & $\mathrm{SP}$ & $-13.07 /-16.00$ & 3.44 \\
\hline 74 & $0.09 / 0.05$ & $\mathrm{SP}$ & $-15.30 /-16.14$ & 1.74 \\
\hline 56 & $0.02 / 0.1$ & $\mathrm{SP}$ & $-\mid 8.30 /-19.61$ & 0.85 \\
\hline 80 & $0.1 / 0.1$ & $\mathrm{SP}$ & n.d. & 2.3 \\
\hline 71 & $0.1 / 0.1$ & SP & $-23.46 /-22.7 \mid$ & 1.88 \\
\hline 73 & $0.2 / 0.03$ & $\mathrm{SP}$ & n.d. & 1.11 \\
\hline 71 & $0.2 / 0.2$ & $\mathrm{SP}$ & $-27.58 /-23.97$ & 1.42 \\
\hline 57 & $0.02 / 0.2$ & $\mathrm{SP}$ & $-|I|||-9.84$. & 2.61 \\
\hline 49 & $0.01 / 0.3$ & SP & $-1.97 /-3.41$ & 1.23 \\
\hline 72 & $0.1 / 0.3$ & $\mathrm{SP}$ & n.d. & 1.74 \\
\hline 49 & $0.2 / 0.3$ & $\mathrm{SP}$ & $-27.37 /-24.82$ & 0.98 \\
\hline 82 & $0.3 / 0.3$ & SP & n.d. & 1.93 \\
\hline 49 & $0.4 / 0.3$ & $\mathrm{SP}$ & $-20.62 /-22.50$ & 2.76 \\
\hline 59 & $0.5 / 0.3$ & SP & $-32.02 /-33.10$ & 1.45 \\
\hline 56 & $0.4 / 0.5$ & $\mathrm{SP}$ & $-31.36 /-33.64$ & 1.66 \\
\hline 28 & $0.5 / 0.4$ & $\mathrm{SP}$ & n.d. & 1.96 \\
\hline 62 & $0.4 / 0.5$ & $\mathrm{SP}$ & $-13.40 /-17.64$ & 1.56 \\
\hline 76 & $0.5 / 0.6$ & $\mathrm{SP}$ & $-31.66 /-31.22$ & 1.67 \\
\hline 39 & $0.7 / 0.7$ & SP & $-10.22 /-25.48$ & 1.87 \\
\hline 65 & $0.7 / 0.7$ & $\mathrm{SP}$ & $-10.22 /-8.66$ & 2.67 \\
\hline 74 & $0.7 / 0.7$ & $\mathrm{SP}$ & $-20.91 /-3.33$ & 2.42 \\
\hline 32 & $0.8 / 0.7$ & SP & n.d. & 2.05 \\
\hline 58 & $0.8 / 0.7$ & $\mathrm{SP}$ & $-8.17 /-5.00$ & 2.85 \\
\hline 55 & $0.9 / 0.9$ & $\mathrm{SP}$ & $-0.77 /-2.10$ & 2.55 \\
\hline 34 & $0.9 / 0.9$ & SP & $-4.44 /-6.29$ & $\mathrm{I} .84$ \\
\hline
\end{tabular}


Table I (Continued)

\begin{tabular}{lllll}
\hline Age & Visual acuity (R/L) & Genetic type & Visual field MD (dB) (R/L) & ET-I (pg/mL) \\
\hline 28 & $0.9 / 0.9$ & SP & $-14.39 /-16.53$ & 2.09 \\
54 & $1.2 / 1.2$ & SP & $-8.83 /-11.07$ & 1.53 \\
49 & $1.2 / 1.2$ & SP & $-13.35 /-11.51$ & 1.47 \\
27 & $1.2 / 1.2$ & SP & $-18.74 /-14.46$ & 2.06 \\
66 & n.d. & n.d. & n.d. & 1.05 \\
\hline
\end{tabular}

Abbreviations: ET-I, endothelin- I; HM, hand motion; LP, light perception; RP, retinitis pigmentosa; ADRP, autosomal dominant RP; ARRP, autosomal recessive RP; SP, sporadic RP; XLRP, X-linked RP; n.d., not determined.

syndrome) aged $56.4 \pm 15$ years, and 20 healthy-eye control subjects, aged $55.8 \pm 8$ years, with no history of systemic hypertension or diabetes mellitus were recruited. Informed consent was obtained from all subjects. The study was performed in accordance with our institution's guidelines and the Declaration of Helsinki on Biomedical Research Involving Human Subjects, and the protocol was approved by the Clinical Research Ethics Board of the Hirosaki University Hospital and Sapporo Medical University Hospital, and their Committees for the Protection of Human Subjects.

After the subjects had rested in the sitting position for 30 minutes, venous blood samples $(5 \mathrm{~mL})$ were taken and plasma was then separated out by centrifugation and frozen at $-30^{\circ} \mathrm{C}$. Prior to measuring the concentration of plasma ET-1, the frozen plasma samples were thawed, and subjected to the Parameter $^{\circledR}$ (R and D Systems, Minneapolis, MN) human ET-1 immunoassay kit. This assay used the quantitative enzyme immunoassay technique. An antibody specific for ET-1 was precoated onto a microplate. Standards, samples, controls, and conjugate were pipetted into wells and any ET-1 present was sandwiched by the immobilized antibody and the enzymelinked antibody specific for ET-1. Following a wash to remove any unbound substances and/or antibody-enzyme reagents, substrate was added to the wells and color developed in proportion to the amount of ET-1 binding. The color development was stopped and the intensity of the color was measured by microplate reader. The measurements were performed in triplicate. Visual fields were examined by Humphrey SITA standard 10-2 threshold automated perimetry (Humphrey Instruments Inc., San Leandro, CA).

\section{Statistical analysis}

All values are expressed as the mean \pm standard deviation (SD) of at least three independent experiments. Data were statistically analyzed with the Mann-Whitney $U$ test for comparison of all groups. Statistical significance was determined as $P<0.01$.

\section{Results}

The clinical characteristics of $50 \mathrm{RP}$ patients including genotypes, age, gender, visual acuity, and mean defect (MD) for the 10.2 visual field are summarized in Table 1. Mean plasma ET-1 concentrations in RP patients $(1.88 \pm 0.30 \mathrm{pg} / \mathrm{mL})$ were lower than those of healthy-eye control subjects $(2.30 \pm 0.30)$. As shown in Table 1, significantly higher $(>2.6 \mathrm{pg} / \mathrm{mL})$ and lower $(<2.0 \mathrm{pg} / \mathrm{mL})$ ET-1 concentrations were recognized in eight and $31 \mathrm{RP}$ patients, respectively. These levels were not statistically different among various genetic types of RP (ADRP, ARRP, and SRP).

In terms of the relationship between plasma ET-1 levels and clinical factors in RP, mean plasma ET-1 levels of more deteriorated in visual acuity (Table 2), and visual field MD (Table 3) was lower than those in the relatively preserved vision group. However, plasma ET-1 values in each patient were variable, and patients with significantly higher and lower ET-1 values did not always show better or worse visual characteristics as above.

\section{Discussion}

ET-1 is produced by vascular endothelial cells and known to be a potent vasoconstrictive peptide. ${ }^{7}$ It has been shown that ET-1 receptors are present in human uveal tissues,${ }^{8}$ the retina, and optic nerve heads, ${ }^{9}$ suggesting that ET-1 may have several physiologic and pathologic roles in the eye. It has been previously reported that abnormal plasma ET-1 levels are found in several ocular diseases, including glaucoma ${ }^{10,11}$ and retinal diseases such as diabetic retinopathy ${ }_{1}^{12}$ retinal vein/artery occlusion, and proliferative vitreoretinopathy, ${ }^{13}$

Table 2 Serum ET-I levels and visual acuity in RP patients

\begin{tabular}{llll}
\hline & \multicolumn{3}{l}{ Visual acuity } \\
\cline { 2 - 4 } & $<0.2$ & $0.2-0.6$ & $>0.7$ \\
\hline Serum ET-I $(\mathrm{pg} / \mathrm{mL})$ & $\mathrm{I} .8 \mathrm{I} \pm 0.62$ & $1.83 \pm 0.5 \mathrm{I}$ & $2.12 \pm 0.40$
\end{tabular}

Notes: Better visual acuity among both eyes was enrolled. A statistically significant difference $(P>0.01)$ was observed between $<0.2$ and $>0.7$.

Abbreviations: ET-I, endothelin- I; RP, retinitis pigmentosa. 
Table 3 Serum ET-I levels and visual field

\begin{tabular}{ll} 
Visual field MD & $(\mathbf{1 0 - 2})$ \\
\hline$<-15 \mathrm{~dB}$ & $<-15 \mathrm{~dB}$ \\
\hline
\end{tabular}

Serum ET-I $(\mathrm{pg} / \mathrm{mL})$

$1.77 \pm 0.53$

$2.14 \pm 0.59$

Notes: Worse MD among both eyes was enrolled. A statistically significant difference $(P>0.01)$ was observed between the two groups.

Abbreviations: ET-I, endothelin-I; MD, mean defect.

in which ocular blood circulation is primarily involved in their pathology.

It was difficult to determine intraocular concentrations of ET-1, because intraocular fluid is necessary. In a previous study, it was reported that ET-1 was recognized in the subretinal fluid of patients with proliferative vitreoretinopathy, and its concentrations were significantly correlated with plasma ET-1 concentrations. ${ }^{13}$ If this is the case, because ET-1 within the peripheral blood circulation most likely penetrates into the intraocular cavity, intraocular ET-1 levels must correlate with plasma ET-1 levels. This suggests that ET-1 is indeed involved in the pathogenesis of several ocular diseases, including RP, and the plasma ET-1 level is a useful marker for evaluation of intraocular hemodynamics. Cellini et al have reported that plasma ET-1 levels were significantly higher in RP patients than those in control subjects, ${ }^{6}$ suggesting that an increase in plasma ET-1 may lead to vasoconstriction, resulting in a decrease in retinal blood flow. ${ }^{3}$ This suggests that abnormally higher levels of plasma ET-1 may also be involved in the pathology of retinal degenerative disease, in addition to the ocular vascular diseases mentioned above. However, in the present study, plasma ET-1 levels of RP patients were not higher than those in the healthy-eye control subjects, and the plasma ET-1 values varied in individual patients. Thus, the contribution of plasma ET-1 levels in the etiology of RP may not be as important as previously suggested. ${ }^{6}$ With regard to the differences between our data and those of others, several possibilities, including different assay systems, race, disease heterogeneity, and disease stages may be involved. In terms of the assay system used, the plasma ET-1 levels of RP patients in our study were comparable with those of Cellini et al but those of our control subjects were significantly lower than levels reported for previous studies. ${ }^{6,11,14}$

Marked attenuation of retinal vessels with sclerotic and atrophic changes of the choriocapillaris layer have been documented in RP. ${ }^{15-17}$ In addition, several morphologic studies have shown thickening of the extracellular matrix surrounding retinal vessels, especially in areas where translocated retinal pigment epithelial cells are close to the vessels following the progressive loss of photoreceptor cells. ${ }^{18}$ On the other hand, several hemodynamic studies have revealed that retinal blood flow is markedly decreased in RP patients compared with normal control subjects. ${ }^{2-5}$ This change in retinal blood flow is quite reasonable because of significant sclerosis of the retinal and choroidal vessels, and the lower requirement for blood flow following degeneration of oxygen-consuming photoreceptors and thinning of the outer retina. Taking all these observations into consideration, it is thought that ET-1 may also be involved in the pathogenesis of RP, as postulated by Cellini et al. ${ }^{6}$ However, the data from our present series of patients suggests that its contribution may be more complex and variable in such a heterogeneous disease group. Thus, evaluating plasma ET-1 levels will contribute to additional insights into the retinal hemodynamics of RP and to development of new therapeutic strategies for preventing retinal degeneration in RP.

\section{Disclosure}

The authors report no conflict of interests in this research.

\section{References}

1. Weleber RG, Gregory-Evans K. Retinitis pigmentosa and allied disorders. In: Ryan SJ. Retina. Vol 1. 4th ed. Philadelphia, PA: Elsevier/ Mosby; 2006:395-498.

2. Langham ME, Kramer T. Decreased choroidal blood flow associated with retinitis pigmentosa. Eye. 1990;4:374-381.

3. Wolf S, Postgens H, Bertram B, Schulte K, Teping C, Reim M. [Hemodynamic findings in patients with retinitis pigmentosa]. Klin Monbl Augenheilkd. 1991;199:325-329. German.

4. Grunwald JE, Maguire AM, Dupont J. Retinal hemodynamics in retinitis pigmentosa. Am J Ophthalmol. 1996;122:502-508.

5. Schmidt KG, Pillunat LE, Kohler K, Flammer J. Ocular pulse amplitude is reduced in patients with advanced retinitis pigmentosa. Br J Ophthalmol. 2001;85:678-682.

6. Cellini M, Santiago L, Versura P, Caramazza R. Plasma levels of endothelin-1 in retinitis pigmentosa. Ophthalmologica. 2002;216: 265-268.

7. Yanagisawa M. A novel potent vasconstrictor peptide produced by vascular endothelial cells. Nature. 1998;332:411-415.

8. MacCumber MW, D’Anna SA. Endothelin receptor-binding subtypes in the human retina and choroid. Arch Ophthalmol. 1994;112: $1231-1235$.

9. Ripodas A, de Juan JA, Roldan-Pallares M, et al. Localization of endothelin-1 mRNA expression and immunoreactivity in the retina and optic nerve from human and porcine eye. Evidence for endothelin-1 expression in astrocytes. Brain Res. 2001;912:137-143.

10. Kaiser HJ, Flammer J, Wenk M, Lüscher T. Endothelin-1 plasma levels in normal-tension glaucoma. Abnormal response to postural changes. Graefe's Arch Clin Exp Ophthalmol. 1995;233:484-488.

11. Ohguro I, Ohguro H, Ohkuro H, et al. Study of contribution of low level of plasma endothelin-1 concentration to pathogenesis of glaucomatous optic neuropathy. Hirosaki Med J. 2006;57:59-64.

12. Oku H, Kida T, Sugiyama T, Hamada J, Sato B, Ikeda T. Possible involvement of endothelin-1 and nitric oxide in the pathogenesis of proliferative diabetic retinopathy. Retina. 2001;21:647-651.

13. Roldan-Pallares M, Rollin R, Mediero A, et al. Immunoreactive ET-1 in the vitreous humor and epiretinal membranes of patients with proliferative vitreoretinopathy. Mol Vis. 2005;11:461-471. 
14. Ergul S, Parish DC, Puett D, Ergul A. Racial differences in plasma endothelin-1 concentrations in individuals with essential hypertension. Hypertension. 1996;28:652-655.

15. Lucas DR. Retinitis pigmentosa: Pathological findings in two cases. Br J Ophthalmol. 1956;40:14-18.

16. Wolter JR. Retinitis pigmentosa, a histologic study with new technique. Arch Ophthalmol. 1957;57:539-544.
17. Szamier RB, Berson EL. Retinal ultrastructure in advanced retinitis pigmentosa. Invest Ophthalmol Vis Sci. 1977;16:947-953.

18. Li ZY, Possin BS, Milam AH. Histopathology of bone spicule pigmentation in retinitis pigmentosa. Ophthalmology. 1995;102: $805-816$.
Clinical Ophthalmology

\section{Publish your work in this journal}

Clinical Ophthalmology is an international, peer-reviewed journal covering all subspecialties within ophthalmology. Key topics include: Optometry; Visual science; Pharmacology and drug therapy in eye diseases; Basic Sciences; Primary and Secondary eye care; Patien Safety and Quality of Care Improvements. This journal is indexed on

Submit your manuscript here: http://www.dovepress.com/clinical-ophthalmology-journal

\section{Dovepress}

PubMed Central and CAS, and is the official journal of The Society of Clinical Ophthalmology (SCO). The manuscript management system is completely online and includes a very quick and fair peer-review system, which is all easy to use. Visit http://www.dovepress.com/ testimonials.php to read real quotes from published authors. 